\title{
Smart parking management system with dynamic pricing
}

\author{
Md Ashifuddin Mondal ${ }^{\mathrm{a}, \mathrm{b}, *}$, Zeenat Rehena $^{\mathrm{b}}$ and Marijn Janssen ${ }^{\mathrm{c}}$ \\ ${ }^{a}$ Department of Computer Science and Engineering, Narula Institute of Technology, Agarpara, Kolkata-700109, \\ India \\ E-mail: ashifuddin.mondal@nit.ac.in \\ ${ }^{\mathrm{b}}$ Department of Computer Science and Engineering, Aliah University, II A/27, New Town, Kolkata-700156, India \\ E-mail: zeenatrehena@yahoo.co.in \\ ${ }^{\mathrm{c}}$ Faculty of Technology, Policy and Management, Delft University of Technology, Delft, The Netherlands \\ E-mail: M.F.W.H.A.Janssen@tudelft.nl
}

Received 13 December 2019

Accepted 29 April 2021

\begin{abstract}
Smart parking is becoming more and more an integral part of smart city initiatives. Utilizing and managing parking areas is a challenging task as space is often limited, finding empty spaces are hard and citizens want to park their vehicles close to their preferred places. This becomes worse in important/posh areas of major metropolitan cities during rush hour. Due to unavailability of proper parking management system, citizens have to roam around a lot in order to find a suitable parking area. This leads to the wastage of valuable time, unnecessary fuel consumption and environmental pollution. This paper proposes a smart parking management system (SPMS) based on multiple criteria based parking space reservation algorithm (MCPR) that allows the driver/owner of vehicles to find and reserve most appropriate parking space from anywhere at any time. The system also considers the concept of dynamic pricing strategy for calculating parking charge in order to gain more revenue by the government agencies as well as private investors. The system employs sensors to calculate concentration index, average interarrival time of vehicles of a parking area for better parking management and planning. The simulation results show that proposed system reduces the average extra driving required by the users to find a parking area and hence it will reduce traffic congestion, which in turn reduces air pollution caused by unnecessary driving to find a proper parking area.
\end{abstract}

Keywords: Smart cities, smart parking, traffic congestion, IoT, sensors, dynamic pricing

\section{Introduction}

Due to the increase in population in the cities there is a need to utilize available resources in a better way. City dimensions are increasing day by day throughout the world and $70 \%$ of the population will live in cities by 2050 [3]. At the same time the number of registered cars are also increasing due to rural to urban migration of people and socio-economical growth. In [33] recent studies show that a car is parked $95 \%$ of its lifetime and run only for the 5\% on an average in a year. Finding a proper parking space in a major metropolitan area becomes more and more challenging day by day. The users are forced to park their cars on the roads which hampers the ongoing traffic. In cities like Nagpur, Pune, Amritsar etc. in India more than $40 \%$ of the road network is being used for on-street parking

${ }^{*}$ Corresponding author. E-mail: ashifuddin.mondal@nit.ac.in. 
[33]. Illegal lane blocking and double parking have several negative impacts, like it further increases traffic congestion in residential areas, increases the risk of accidents for pedestrians and also raises pollution levels [15].Traffic congestion causes billions of monetary loss to the world economy according to statistics (http://www.transport2012. org) presented in a study [9]. Car should be parked in a dedicated car parking infrastructure, however the demand for parking infrastructure will continue to grow as the number of cars in the city is increasing continuously. Hence, effective use of scarce parking space has gained paramount importance in smart cities $[4,10,11,14,24,26]$.

For better parking management, a proper system is needed which will utilize the available parking resources in a smart way for fulfilling ever increasing parking demand and assisting the users to find a proper parking space. Finding a suitable vacant parking space in a major city is a big concern for citizens. The situation becomes worse in those areas near offices, hospitals and market places in peak hours. Without any information, drivers use so-called blind search techniques. In blind search technique [38], the drivers keep searching for a vacant parking space within a certain distance to their destination, as they have no prior parking information. They will stop searching once they find the vacant parking space otherwise continues to search. This kind of searching is time consuming and results in more fuel consumption, air pollution and traffic congestion within the city. A better approach is the informed approach in which parking information is shared with the drivers through smart parking systems where the system publishes the information regarding space availability of parking areas so that the drivers can decide which parking area is most suitable. This kind of system faces problem when number of free parking spaces are limited in rush hour and hence most of the drivers will drive towards these available parking areas. This leads to high traffic congestion and is termed as "multiple-car-chasing-single-space" phenomena [38].

To overcome the problem of "multiple-car-chasing-single-space", a buffered parking information sharing system(BPIS) [38] is introduced where the system intentionally publishes a lesser number of free parking spaces than the actual number to keep a buffer. Hence the system has some extra spaces to deal with the situation when many drivers are looking for these free spaces. But this is not a feasible solution as it is very difficult to determine the number of buffer spaces [38].

Keeping the loopholes of the above mentioned techniques in mind, this paper develops and implements a smart parking management system (SPMS). The proposed SPMS incorporates dynamic pricing technique for determining the cost of parking and it is an important aspect of revenue management [23,30]. The proposed system helps to reduce traffic congestion while searching parking areas, the operational cost of parking and at the same time it increases resource (parking area) utilization. The proposed system assists the drivers/users to search and book a suitable parking area based on users' preferences seamlessly. The user has to pay a certain amount for parking his/her vehicle. Dynamic pricing is a technique which adjusts the price of the product with respect to time according to the demand and supply of the product for more revenue [30]. As compared to fixed pricing scheme, dynamic pricing technique [8] generates more revenue as it will adjust the price of parking slot in a parking area time to time as per demand of parking and availability of the spaces. The owner of these parking areas may be government or private agencies. The proposed system also does the parking surveys by using ultrasonic sensors to track down concentration index, average inter-arrival time of vehicles for efficient management and planning of parking areas. The proposed system relies on IoT and ambient intelligence which can be used for better management of public resources and enhances the quality of services provided to the citizens [7,40]. IoT is a new computing and communication paradigm in which the objects of everyday life are equipped with sensors, micro-controllers and transceivers to sense the surrounding environmental parameters and communicate the sensed data with one another or user and it becomes an integral part of the Internet system [1,5,16]. Ambient intelligence is a multi-disciplinary approach that brings intelligence to our surrounding environment and makes the environment sensitive and responsive to the citizens [12].

The remainder of the paper is organized as follows. Section 2 presents related literature of parking management system. In Section 3, detailed description of the system design of smart parking management system is given. Improved MCPR algorithm is discussed in Section 4. Implementation and evaluation of the system are discussed in Section 5. Finally, the paper is concluded in Section 6. 


\section{Related work}

Car parking problems associated with the growing urbanization have gained considerable attention over the past two decades. Most of the existing researches have focused in the proper reservation of the parking lots and thus mitigates the delay and traffic congestion related to the finding a parking area. Pham et al. [28] introduced a smart parking system which is based on IoT. The system maintains a network of car parking area where each car parking area is treated as a node. Each node maintains the information of neighboring nodes so that it can forward the vehicle to other neighboring car parking area with minimum value of cost function if the current car parking area is full. The system uses the RFID technology in the parking area to monitor car parking status. Another similar work is carried out in [17] where a cloud based car parking system is developed and implemented in a university campus of a smart city. The proposed architecture consists of three layers: sensor layer, communication layer and application layer. In the application layer different types of business services like car parking locator, car tracking service etc. are deployed in the cloud. The deployed sensors send the updated parking information to the information station which is installed in the car parking lots and in turn it sends the data to information centre in the cloud. In cloud tier a number of maps/reduce algorithms are used like recommendation algorithm for suggesting best parking lot. User can interact with the system through corresponding car parking application on their mobile devices and gets the best available car parking lots. In other studies [18,38], it is found that drivers look at the LED display board to check availability of vacant spot and reserve the free parking space. The LED display board shows how many vacant spaces there are and the type of those vacant spaces. The display board is set up in the entrance of a parking lot.

In contrast to the above systems, in [13] the authors designed a smart parking system framework which guides the users to find and reserve optimal resource based on user objective function using mixed integer linear programming. The intelligent parking assistant (IPA) [15] is proposed to manage the off-street public parking spaces and system ensures that the parking spaces can only be used by authorized users after reservation at IPA website. The reservation will be held for a grace period (e.g. 15 minutes) and if the user is not able to come to the spot within that period, an SMS will be sent to the respective user about expiration of reservation. This IPA system is based on wireless sensor network like other intelligent parking management systems [21,25,27,34,36,37,39]. In a similar vein, a smart car parking system-iParker [20] proposed an intelligent resource allocation and reservation model. The authors used mixed integer linear programming (MILP) mathematical model to maximize the resource utilization whereas minimizes the total price of parking for the users. The paper also presented dynamic pricing policies to increase the revenue for parking managers. In another study [35], the authors proposed smart parking architecture based on fog computing. The system consists of fog nodes those are deployed in parking lots to collect the parking lots information. These fog nodes collaborate and share the parking data with each other to generate proper parking information of the parking area. These fog nodes disseminate parking lot status to the users and interested ones can send parking requests back to the fog nodes. Fog nodes then process the parking request based on Greedy allocation technique. Apart from finding a parking area for the users, some researchers focused on parking survey in intelligent parking system [6]. They used magnetic sensors to obtain the occupancy status of parking lots and proposed three different layouts of magnetic sensors in a parking lot to do the parking survey.

In all the above mentioned studies, the authors consider only dedicated parking infrastructure for car parking. In contrast to this, a parking guidance system [22] has been presented which guides the drivers for on-street parking spots, rather than dedicated parking infrastructure. The proposed system does not require any investments on parking infrastructure; it only requires information about probability of finding parking spots on streets. For that, authors used historical data those are available from smart parking meters. Based on these data, the system guides the drivers with sequence of streets that they should look for while searching for a parking spot with high chance of finding a spot.

Some research works also investigated the different ways to determine the parking price. For example, in [2], the authors proposed a dynamic and demand-based pricing model to optimally manage parking resources in a busy urban city. They explicitly addressed the interactive relationship between pricing and parking demand via a dynamic MPEC model. Another study [29] proposed a dynamic parking pricing model to achieve optimal flow pattern in a network. 
The above mentioned systems has some limitations like in [28], the system will forward the vehicle to another neighbor node with minimum cost function if the current parking area is full. Hence time and fuel will be wasted in that scenario; also it elevates traffic congestion in the roads. In [18], drivers can get the information of parking space availability only after the user reaches the car parking spot. Hence the users have to go to other parking area if current parking area is full which leads to wastage of time, cost and hampers traffic flow. In [38], the system suggests the parking area to the user based only on availability factor. The system does not consider users' preferences like price of parking, distance of parking area from destination. In order to overcome the shortcomings of the above mentioned systems, this paper propose a smart parking management system based on MCPR Algorithm [31] which utilizes the available parking resources in an efficient way by considering the users' preferences like cost of parking and distance between parking area and the destination.

\section{The proposed system framework}

The SPMS consists of various elements. Figure 1 shows the proposed smart parking management system (SPMS) framework. The users of the system i.e. car drivers have to register themselves with some information, like vehicle no., owner name, driver name, license no. etc. Then the user can search for parking area after logging in to the system. It may provision that the proposed system interact with the regional transport office database server for authentication of vehicles as well as it will check vehicle tax payment status. In this way unauthorized vehicles and drivers cannot use the system, which contributes to safety and increases the revenue of the government. After successful authentication, the SPMS web server finds the most suitable parking area based on user's preferences and space availability of the parking area. Space availability status of parking slots of every parking area are automatically captured by ultrasonic sensors and that information is sent to the parking area database. On the other hand, the MCPR algorithm [31] is used to find the most suitable parking area based on user's preference and space availability of the parking area and it is running in centralized web server. A brief discussion of the MCPR algorithm is described in the Section 3.1. The details of parking area like parking area name, address, and price per hour decided by the system is sent to the user and he/she can reserve the parking space. After booking or leaving the parking area, the space availability status of that parking area will be changed and parking area database will be updated. User has to pay the amount determined by the system which is based on dynamic pricing scheme. The interaction among the objects of the system is shown in Fig. 2. It emphasizes the messages passed and order of interaction among the objects.

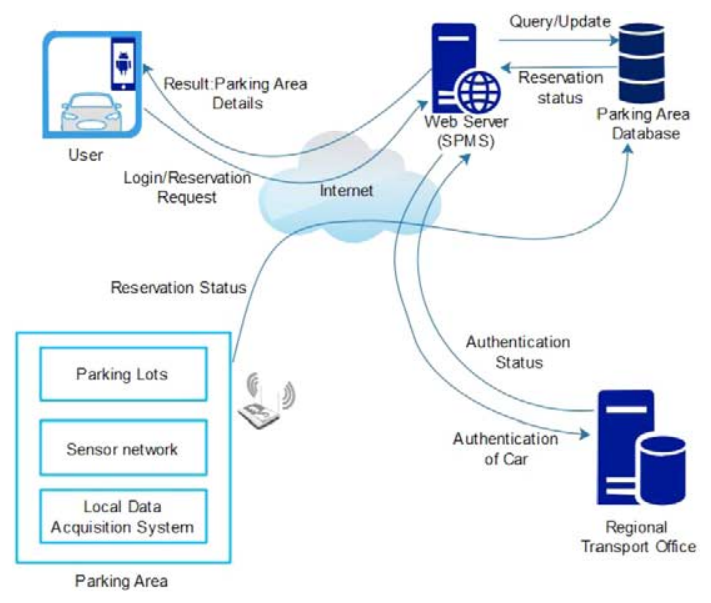

Fig. 1. System framework of SPMS. 


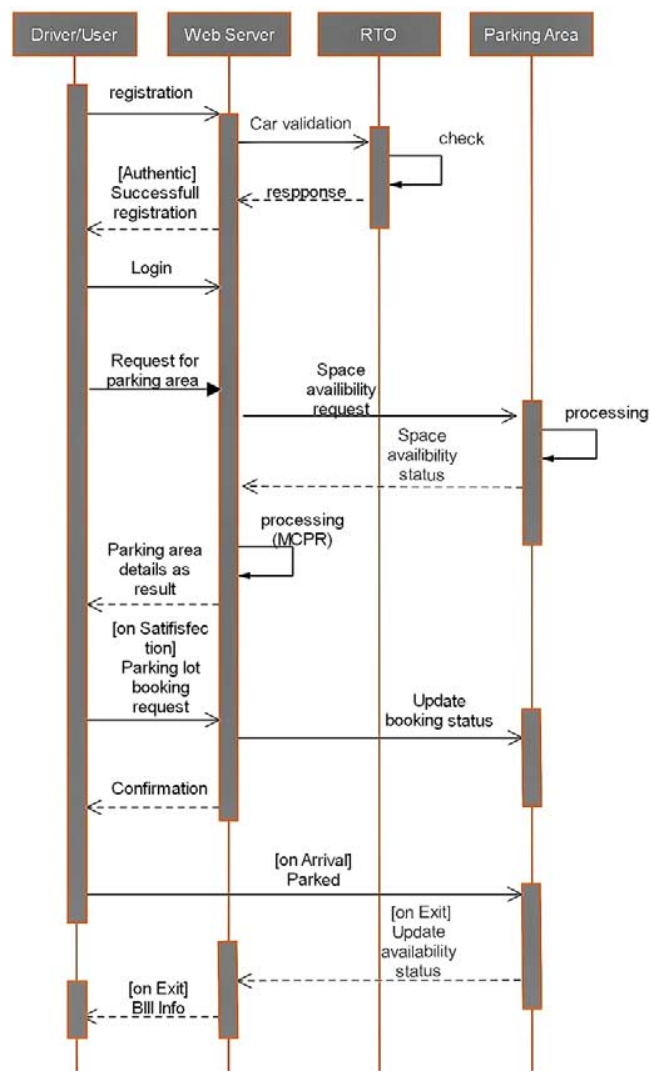

Fig. 2. Interaction diagram among the objects.

\subsection{Brief overview of MCPR algorithm}

MCPR algorithm [31] finds the best possible parking area amongst the available alternatives using the different criteria given by the users. It uses the multi criteria decision analysis (MCDA) technique [19]. In MCPR, it is assumed that each parking area has different number of parking spaces where vehicles can be parked. The registered available parking areas have been considered as the alternatives for this algorithm.

The available parking areas $\left(P A_{1}, P A_{2}, \ldots, P A_{n}\right)$ are considered as different alternatives where $n$ is the number of available parking areas. Further, in MCPR it is considered that each $P A_{i}$ has several parking slots. The objective of this algorithm is to find a parking space amongst these alternatives, i.e. $P A_{i}$, where $1 \leqslant i \leqslant n$. MCPR considered three criteria: i) Distance between parking area and the destination. This is considered as criteria $\mathrm{C} 1$. ii) Price per hour for reserving the space, i.e. criteria C2. iii) Unoccupied space for each parking area and it is considered as criteria $\mathrm{C} 3$. Here, MCDA technique has been used to choose one alternative amongst the available alternatives based on the mentioned criteria. For that, MCDA calculates the utility factor for each alternative. The utility $U$ for each alternative $O_{i}$ is defined in the following equation as:

$$
U\left(O_{i}\right)=\sum_{k=1}^{m} Z_{k}\left(O_{i}\right) \times W_{k}, \quad i=1,2, \ldots, n
$$

where, $Z_{k}\left(O_{i}\right)$ is the normalized score of alternative $O_{i}$ under criterion $C_{k}$ and $W_{k}$ is the weight of importance for criterion $C_{k}$. Then, these alternatives are ranked in descending order and the alternative(i.e. parking area) with highest utility value is selected as the best possible parking area. The detailed calculations and illustrations of the MCPR algorithm and MCDA are shown in [31]. 


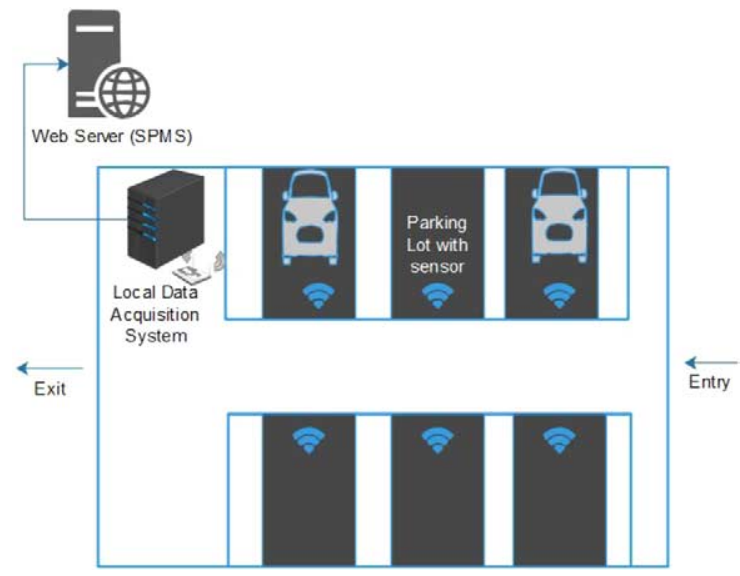

Fig. 3. A prototype of the parking area.

\subsection{Overview of the system components}

This section describes different components of SPMS system in detail. The system consists of three parts: i) user, ii) parking area and iii) web-based decision support system.

\subsubsection{User of the system:}

The system is used by two types of users: vehicle owner or driver and parking owner. Vehicle owner or driver can search and make a parking slot booking request to the server through android based hand held devices. While parking owners can register their resources with the system and become parking resource owner after investigation by the authorities. The contributor of the parking resource in the system may be government agencies or private investors. The parking owners have the responsibility to setup their parking areas according to the prototype shown in Fig. 3.

\subsubsection{Parking area:}

Every parking area consists of a number of parking spaces i.e. parking slots with predefined parking capacity and state of parking area will change on either booking of space or leaving the space with respect to time. For monitoring real time space availability status, each parking area has to be equipped with ultrasonic sensor or similar equipment. The sensor network [32] is responsible for tracking space availability status and delivers the same to the web-based decision support system. Ultrasonic sensors are deployed on the ground of each parking lot which detects whether the parking space is occupied by a car or not. It also detects the event when car leaves the space. These sensors are attached with a micro-controller which counts the number of spaces occupied and conveys the parking space availability status to the SPMS web server. The design prototype of the parking area is shown in Fig. 3 . The system automatically calculates the concentration index and average inter-arrival time for each parking area by using sensors for efficient parking management and planning. Parking areas of the proposed system are characterized by concentration index and average inter-arrival time. These are used to identify the demand and popularity of the respective parking area. These are defined as follows:

a) Concentration index: Concentration index is defined as the ratio of total number of cars parked in the parking slots at a given time to the total parking capacity of a particular parking area. Concentration index of parking area at any instance can be determined according to the proposed layout of parking area as shown in Fig. 3. Let us assume, $P A_{i}$ is a parking area with $m$ no. of parking slots, $N_{t}$ is the number of vehicles present in $P A_{i}$ at time $t, C\left(P A_{i}\right)$ is the capacity of parking area $P A_{i}$ and $O S_{j}$ is occupancy status of each parking slot in a parking area. Then the concentration index is expressed as:

$$
\delta_{t}\left(P A_{i}\right)=N_{t} / C\left(P A_{i}\right)
$$


where

$$
N_{t}=\sum_{j=1}^{m} O S_{j} \quad \forall O S_{j}=1
$$

and $P A_{i}=1,2,3, \ldots, m$.

$O S_{j}=1$, if vehicle present, otherwise it is zero. The value of concentration index lies between zero to one. Higher the value of concentration index, lesser will be the number of vacant parking slots. This means that, demand for parking is high in that parking area and may be more number of parking areas are required. Hence, based on the concentration index, traffic authority, and or parking area managers can devise future plans about whether more parking slots are required or not in a particular parking area.

b) Average inter-arrival time: It is the average time between successive arrivals of vehicles over a time period. It is expressed by the following equation:

$$
\lambda_{t}\left(P A_{i}\right)=\sum_{i=1}^{n-1}\left(A_{i+1}-A_{i}\right) / n-1
$$

Where, $n$ is the number of vehicles arriving over a time period $t . A_{i}$ is the arrival time of $i^{\text {th }}$ vehicle. $A_{i+1}$ is the arrival time of $(i+1)^{\text {th }}$ vehicle. Lesser the value of average inter-arrival time, more is the utilization of parking area and hence higher is the demand of parking area.

\subsubsection{Web based decision support system:}

The decision support system is a centralized web-based system which accepts user's reservation requests, finds the most appropriate parking slot for the user and convey the details of that parking space to the user's hand held device. The MCPR algorithm [31] running in the SPMS web server is responsible for selecting the most appropriate parking area based on user's preference and current parking area status. The web service comprises of several modules hosted in cloud environment shown in Fig. 4.

a) Registration module: Users have to register themselves to the proposed system before using the system. Two types of users are there: car driver or owner and parking area owner. Car drivers or owners have to provide detailed information about vehicle and driver for registration. Also parking area owners have to register themselves into the system to become a part of it.

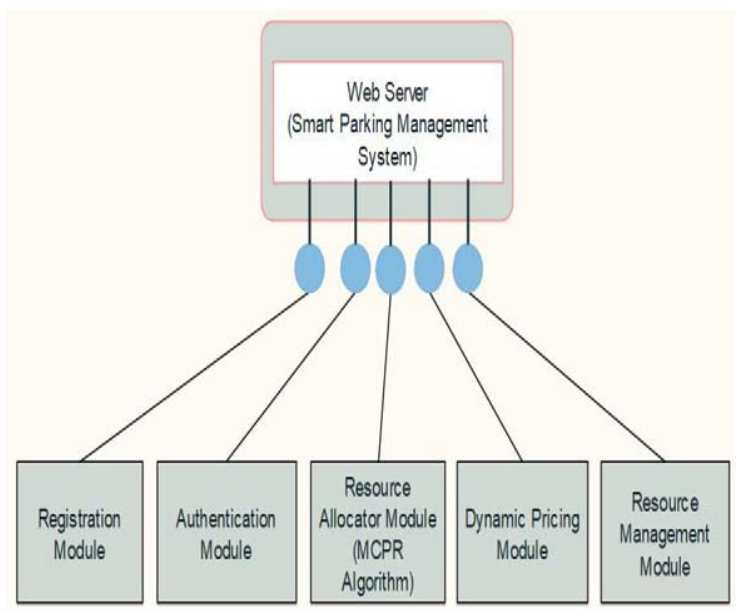

Fig. 4. Modules of SPMS web server. 
b) Authentication module: This module is responsible for the authentication of vehicles. When the users register their vehicles in the system, they have to provide details like vehicle no., license no. of driver, etc. During registration procedure, the system will interact with the regional transport office (RTO) to check whether vehicle no. is valid or not. Regional transport office maintains a database for all the registered vehicles and their corresponding tax payment status. If a vehicle is not in the RTO database or tax payment is due, then the system will not allow the car owner to park.

c) Resource Allocator Module: After registration and verification is done, users can now find and make a booking request for a parking slot to the SPMS system. The Resource Allocator Module is responsible for finding the available parking resources and so the MCPR algorithm is used here. To calculate the price of parking, the resource allocator module invokes the dynamic pricing module. The selected parking areas are then sent to the users hand held device. If the user is satisfied with the parking area shortlisted by the resource allocator module, then he/she can make a booking request. Once the resource allocator module receives the parking request, it allocates that parking area to the corresponding user. At the same time it will update the database regarding the number of available parking slots of a parking area.

d) Dynamic pricing module: This module decides the amount of price user has to pay. Different parking areas may have different parking prices per hour. But the price is not static or fixed, instead the price changes dynamically over time based on dynamic pricing model. Dynamic pricing model is a way of increasing the revenue when demand is high. The Price of $i^{t h}$ parking area $P_{t}^{i}$ at instance $t$ represented by Eq. (5). Here, $P_{t}^{i}$ is the price of parking on per hour basis.

$$
P_{t}^{i}=O C_{i}+\left(O C_{i} * U_{t}^{i}\right)+L C
$$

$P_{t}^{i}$ has three components: i) Operational Cost $\left(O C_{i}\right)$ at $i^{\text {th }}$ parking area, ii) Utilization factor $\left(U_{t}^{i}\right)$ and iii) Late_arrival Cost $(L C)$.

- Operational Cost $\left(O C_{i}\right)$ : The operational cost includes electric cost, maintenance cost, human resource cost etc.

- Utilization factor $\left(U_{t}^{i}\right)$ : The utilization factor is proportional to the parking occupancy ratio $\left(O_{t}\right)$ at instance $t$ and it is represented by Eq. (6). The parking occupancy ratio is the ratio of the total number of occupied spaces at a specific instance to the total parking capacity of a parking area and is represented by Eq. (7).

$$
U_{t}^{i}=k * O_{t}
$$

and

$$
O_{t}=O C U_{t}^{i} / C_{i}
$$

where, $O C U_{t}^{i}$ represents no. of occupied spaces at instance $t$ in $i^{\text {th }}$ parking area and $C_{i}$ is the total capacity of $i^{\text {th }}$ parking area.

- Late_arrival Cost $(L C)$ : The third component effects the dynamic pricing when the user will arrive late in the booked parking area. If the users are unable to reach within the stipulated time, an extra amount will be charged by the parking owner due to late arrival. In this work, it is assumed that if a user is unable to reach within 1 hour of booking then, he or she has to pay an extra amount based on the parking occupancy ratio at that point of time when reached $\left(O_{t+j}\right)$ with respect to the price of booking, where $j$ is represented in minutes. Now, the component $L C$ is represented by Eq. (8).

$$
L C= \begin{cases}0, & \text { if reach on time } \\ P_{t}^{i} *\left(O C U_{t+j}^{i} / C_{i}\right), & \text { if reach late }\end{cases}
$$


Substituting the value of $\left(U_{t}^{i}\right)$ in Eq. (5), $P_{t}^{i}$ can be expressed as below:

$$
P_{t}^{i}=O C_{i}\left(1+k * O C U_{t}^{i} / C_{i}\right)+L C
$$

This equation calculates parking cost on hourly basis. At the time of booking, if the user books the parking slot for $n$ hours then the total parking cost $T P$ will be calculated by using the equation given bellow:

$$
T P=n * P_{t}^{i}
$$

If the user decides to extend the parking hour duration later on, then he/she has to pay an extended hour charge $E H C$ depending upon the parking occupancy ratio for the next hour $\left(O_{t+1}\right)$ along with the cost charged for the previous hour. It can be represented by the following equation:

$$
T P=\left(P_{t}^{i}+\sum_{j=1}^{n} P_{t}^{i} * O_{t+j}\right)
$$

Here, $n$ is the number of hours. While calculating the cost of parking, the Eq. (9) of dynamic pricing model covers many important aspects, such as:

- It not only considers the availability of parking slots, but it also considers parking booking demand at an instance while determining the price of parking with the help of utilization factor $\left(U_{t}^{i}\right)$ component. When parking demand is high, then price will be increased based on Eq. (6).

- If a particular parking slot is booked by a user but he/she reached the parking slot late then that specific slot remains unutilized for a long time. As the system charges the price of parking only for the duration of stay in the parking area, not the duration from booking to leaving the parking slot, the parking owner will suffer monetary loss apart from under-utilization of the resources. That is why the Late_arrival Cost $(L C)$ component is included in the dynamic pricing which will charge an extra amount to compensate for late arrival in the booked parking slot.

- The proposed dynamic pricing model also considers the extended hour charge $E H C$ based on demand of the parking slot represented in Eq. (11). Higher the demand, higher will be the extended hour charge.

Operational cost $\left(O C_{i}\right)$ is determined by the owner of the parking area while utilization factor $\left(U_{t}^{i}\right)$ depends on parking slot occupancy ratio represented by Eq. (7). $K$ is a constant and value of $K$ is also assigned by the owner of the parking area based on trial and run. This paper considers value of $K$ as 0.5 . Table 1 illustrates the proposed dynamic pricing model. It is assumed that capacity of $i^{\text {th }}$ parking area $\left(C_{i}\right)$ is 200, operational cost at $i^{\text {th }}$ parking area $\left(O C_{i}\right)$ is Rs. 30, constant $k=0.5$, user booked the parking lot for 1 hour and arrived on time. Table 1 shows that as the demand increases, the price of the parking area also increases.

To demonstrate the cost of parking in case of late arrival, it is assumed that the initial cost of parking was Rs. 31.5 and $O_{t}=0.1$. Now, if the user arrives late in the booked parking slot, then the parking price depends on parking occupancy ratio $\left(O_{t+j}\right)$ of the current time i.e. when the user has reached. Table 2 shows price of parking in case

\begin{tabular}{lccc}
\multicolumn{4}{c}{ Table 1 } \\
\multicolumn{3}{c}{ Price of parking (Reach on time) } \\
\hline$O C U_{t}^{i}$ & $O_{t}$ & $U_{t}^{i}$ & $\begin{array}{c}P_{t}^{i} \text { (in Rs.) } \\
\text { Reach in time }\end{array}$ \\
\hline 20 & 0.1 & 0.05 & 31.5 \\
40 & 0.2 & 0.1 & 33 \\
80 & 0.4 & 0.2 & 36 \\
120 & 0.6 & 0.3 & 39 \\
150 & 0.75 & 0.37 & 41.25 \\
190 & 0.95 & 0.48 & 44.25 \\
\hline
\end{tabular}


Table 2

Price of parking (Reach late)

\begin{tabular}{lccc}
\hline$O C U_{t+j}^{i}$ & $O_{t+j}$ & $\begin{array}{c}L C \\
\text { (in Rs.) }\end{array}$ & $\begin{array}{c}P_{t}^{i} \text { (in Rs.) } \\
\text { Reach late }\end{array}$ \\
\hline 60 & 0.3 & 9.45 & 40.95 \\
80 & 0.4 & 12.60 & 44.10 \\
100 & 0.5 & 15.75 & 47.25 \\
120 & 0.6 & 18.90 & 50.40 \\
140 & 0.7 & 22.05 & 53.55 \\
160 & 0.8 & 25.20 & 56.50 \\
\hline
\end{tabular}

Table 3

Extended hour charge

\begin{tabular}{lccccc}
\hline$O C U_{t+1}^{i}$ & $O_{t+1}$ & $P_{t}^{i}$ (in Rs.) & $E H C$ (in Rs.) & \multicolumn{2}{c}{$T P$ (in Rs. for 2 h) } \\
\cline { 5 - 6 } & & for 1st h & 2nd h & 1st h +2 nd h & At the time of booking \\
\hline 60 & 0.30 & 31.5 & 40.95 & 72.45 & 63 \\
70 & 0.35 & 31.5 & 42.53 & 74.03 & 63 \\
80 & 0.40 & 31.5 & 44.10 & 75.60 & 63 \\
90 & 0.45 & 31.5 & 45.68 & 77.18 & 63 \\
100 & 0.50 & 31.5 & 47.25 & 78.75 & 63 \\
110 & 0.55 & 31.5 & 48.83 & 80.33 & 63 \\
120 & 0.60 & 31.5 & 50.40 & 81.90 & 63 \\
130 & 0.65 & 31.5 & 51.78 & 83.28 & 63 \\
\hline
\end{tabular}

of late arrival. It shows the change in price with respect to change in $O_{t}$ considering the initial booking price of Rs. 31.5 from Table 1. It is also shown that if the parking occupancy ratio $\left(O_{t+j}\right)$ is high at the time of late arrival, the amount of extra charge which user has to pay also increases. Table 2 shows $L C$ and total price, $P_{t}^{i}$.

To demonstrate the extended hour charge $(E H C)$, let's consider the scenario from Table 1: user had booked the parking slot for 1 hour and at the time of booking $O C U_{t}^{i}$ was 20, $O_{t}=0.1$ and the initial cost of parking was Rs. 31.5. Later on user decides to extend the duration of booking for another 1 hour. In that case, users have to pay for 2 hours. The extended hour charge for the next 1 hour depends upon the parking occupancy ratio $\left(O_{t}\right)$ of that parking slot at time $t+1$. Table 3 illustrates the extended hour charge for the next hour and total amount (TP) using Eq. (11) for parking of 2 hours. From the table, it is clear that if a user initially booked the parking slot for 2 hours, he/she has to pay Rs. 63 whereas if he/she later on decides to park for 1 more hour and at that point of time if the number of occupied parking slots $O C U_{t+1}^{i}$ is 60 , then he/she has to pay Rs. 72.45 as the $E H C$ is also included in the total cost.

e) Resource management module: This module manages the resources i.e. parking areas and parking slots. When someone (i.e. private or government agency) wants to add his/her parking area as a parking resource into the system, then this module adds the parking area after proper authentication. In a particular parking area, a new parking slot can be added or can be removed.

\section{Improved MCPR}

The MCPR algorithm discussed in Section 3.1 did not consider the scenario where a user books a particular parking slot of a recommended parking area, but didn't reach there and hence the booked parking slot was not used. In that case, parking owner will suffer monetary loss. Apart from that, the other users who require the same parking area at the same point of time will not get the opportunity to park their cars as it is already booked by another user. Hence it will lead to under-utilization of resources i.e. parking areas. To address this issue, the algorithm is improved and shown by Algorithm 1. In the improved MCPR algorithm, it considers the time gap between parking reservation 


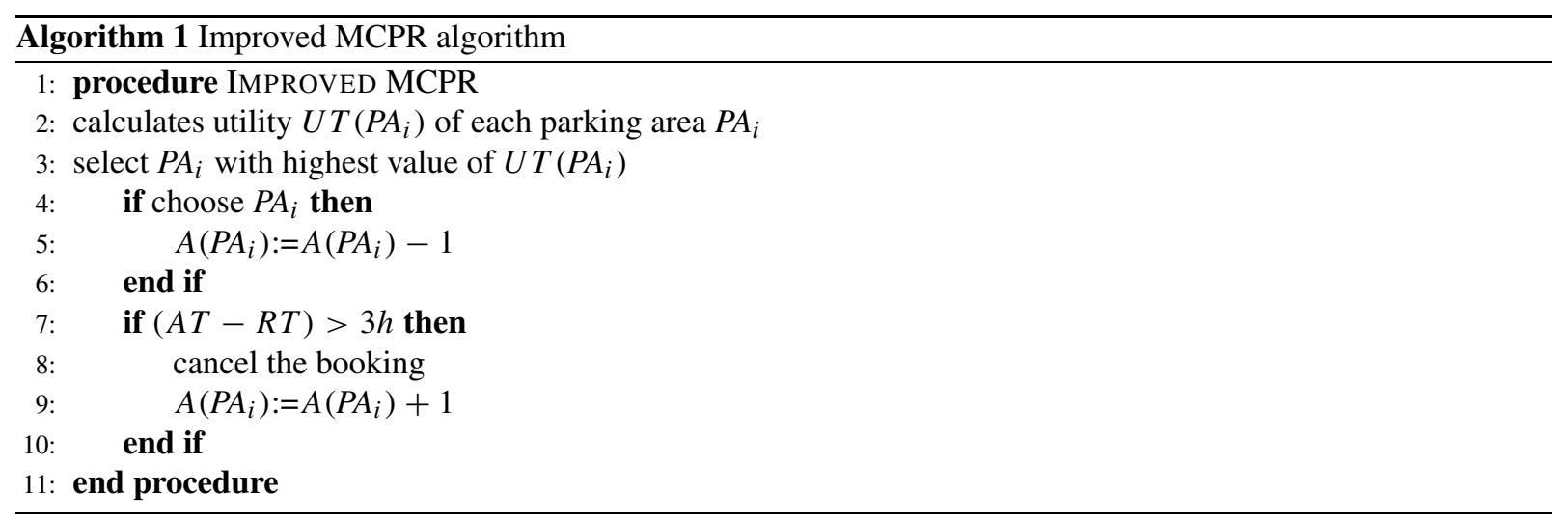

request time $(R T)$ and arrival time to that parking area $(A T)$. This time gap is termed as waiting window. If the time gap is more than 3 hours, then it will cancel the booking request. Hence, it will update the availability status of that parking area by de-allocating that specific parking slot. If the availability of parking slots at parking area $P A_{i}$ is $A\left(P A_{i}\right)$, then after the automatic cancellation of booking, $A\left(P A_{i}\right)$ will be updated as $A\left(P A_{i}\right)+1$.

\section{Implementation and evaluation}

In this section, the implementation of the proposed system is presented. The implementation enables the simulation of the system. The simulation result is used to compare the performance of our system with other systems on several criteria.

\subsection{Experimental setup}

The implementation of the proposed smart parking management system has been carried out by developing three components 1) implementation of a prototype of parking area, 2) web-based decision support system and 3) mobile application of SPMS for users.

To implement the prototype parking area as mentioned in Section 3.2.2, arduino uno board has been used as a micro-controller. The ultrasonic sensor is attached with the arduino uno board and it tracks the status of the parking slot i.e. presence and absence of vehicles in a certain parking area and sends the information to the remote parking area database. The ESP8266 module has been used to send the information through wireless communication from the parking area to the remote parking area database.

The Web-based decision support system of the proposed SPMS is implemented using PHP framework with mysql database. Android SDK is used to develop the mobile application of SPMS for android platform. Using this mobile application, car owners or drivers can search as well as make a request to book a parking slot to the web-based decision support system.

\subsection{Experimental result and simulation}

Based on the implementation, an experiment is designed and simulations are run. Figure 5 and 6 represents the serial monitor of arduino uno IDE. Figure 5 shows that a vehicle has entered a parking slot. When a car has entered, it is detected by ultrasonic sensor by measuring the distance between the bottom of the car and the deployed sensor. In this experiment, if the distance is within 10 inch then it is considered that a car has entered in the parking slot. The measured distance values (two units i.e. inch and $\mathrm{cm}$ in two columns) are shown in Fig. 5. On the other hand, Fig. 6 shows that a vehicle has left the parking slot and that information is sent to the SPMS web server's parking database wirelessly through ESP8266 module. Based on the same principle, ultrasonic sensor detect whether a car has left the parking slot or not. If the distance is more than $10 \mathrm{inch}$, sensor considers that there is no car in the parking slot. That is how the occupancy status of each parking slot of a parking area is tracked and sent to the parking area database. 


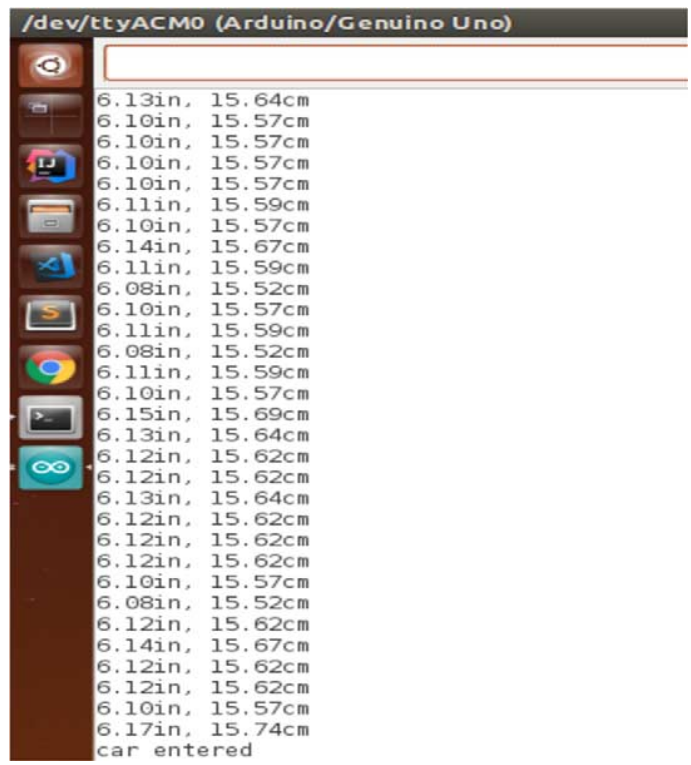

Fig. 5. Serial monitor: tracking of occupancy status of parking slot.

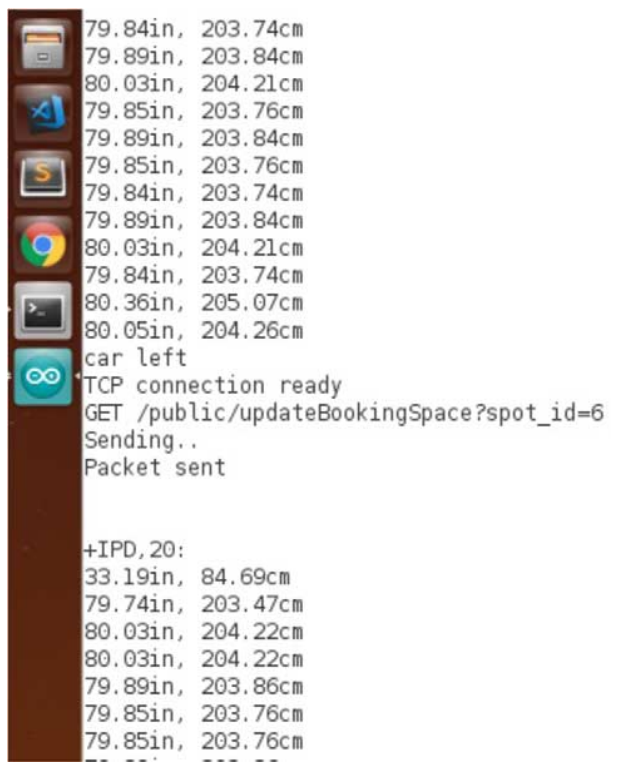

Fig. 6. Serial monitor: sending occupancy status to SPMS server.

The database format for the detecting occupancy status of each parking slot of a parking area is represented in Table 4. By using this data, the concentration index and average inter-arrival time are calculated using Eq. (2) and Eq. (4). By considering the time period $t=8: 00: 00 \mathrm{AM}$ to 8:15:00 AM of a parking area $P A_{i}$ with parking capacity $=10$, the concentration index $\delta_{t}\left(P A_{i}\right)$ becomes 0.7 and average inter-arrival time $\lambda_{t}\left(P A_{i}\right)$ becomes 150 seconds.

Table 5 shows the concentration index and average inter-arrival time of each parking area for the duration of 15 minutes. The concentration index and average inter-arrival time are used to identify the high demanding and/or low demanding parking areas. Hence, this can help regulatory bodies to plan better parking area management strategies like whether more parking areas will be needed or not on that particular area based on concentration index and average inter-arrival time. 
Table 4

Database format of vehicle occupancy status

\begin{tabular}{lcccc}
\hline Sensor ID & Occupancy status & In time & Out time & Vehicle no. \\
\hline US1001 & 1 & $8: 00: 00 A M$ & $8: 45: 00 A M$ & WB20Z8737 \\
US1002 & 1 & $8: 01: 00 A M$ & $8: 25: 00 A M$ & WB20Z2987 \\
US1003 & 1 & $8: 01: 00 A M$ & $8: 45: 00 A M$ & WB27A5437 \\
US1004 & 0 & - & - & - \\
US1005 & 0 & - & - & - \\
US1006 & 1 & $8: 03: 00 A M$ & $9: 00: 00 A M$ & WB42A1525 \\
US1007 & 1 & $8: 07: 00 A M$ & $8: 50: 00 A M$ & WB20Z3467 \\
US1008 & 1 & $8: 10: 00 A M$ & $9: 05: 00 A M$ & WB27A1008 \\
US1009 & 0 & - & - & - \\
US1010 & 1 & $8: 15: 00 A M$ & $9: 10: 00 A M$ & WB42A1122 \\
\hline
\end{tabular}

Table 5

Concentration index and average inter-arrival time in sample parking area

\begin{tabular}{lrccc}
\hline Parking area & Capacity & Occupied & $\begin{array}{c}\text { Concentration } \\
\text { index }\end{array}$ & $\begin{array}{c}\text { Avg. Inter-arrival time } \\
\text { (in seconds) }\end{array}$ \\
\hline PA1 & 100 & 95 & 0.95 & 37.89 \\
PA2 & 85 & 85 & 1 & 42.35 \\
PA3 & 100 & 80 & 0.8 & 45 \\
PA4 & 70 & 68 & 0.97 & 52.94 \\
PA5 & 50 & 20 & 0.4 & 180 \\
PA6 & 70 & 50 & 0.71 & 72 \\
PA7 & 80 & 50 & 0.62 & 72 \\
PA8 & 100 & 70 & 0.7 & 51.43 \\
PA9 & 50 & 38 & 0.76 & 94.74 \\
PA10 & 60 & 20 & 0.33 & 180 \\
\hline
\end{tabular}

The value of the concentration index ranges between 0 to 1 . The value 1 represents a high concentration index which indicates that corresponding parking area has no vacant parking slot while 0 is the lowest concentration index i.e. all the parking slots are available for parking in the corresponding parking area. Figure 7 and Figure 8 compare the concentration index and average inter-arrival time of different parking areas respectively. From Fig. 7, it is seen that parking area "PA2" has the highest concentration index while parking area "PA10" has the lowest concentration index.

Based on the occupancy status of the parking area and users' preferences, the SPMS web based decision support system finds the most suitable parking area for the users. Figure 9 shows some of the android application interfaces of SPMS. Figure 9 (a) is the user registration interface. Figure 9(b) shows login interface. Figure 9 (c) shows the interface where the user has to enter the destination address. The interface also provides users to choose parking preferences in terms of the cost of parking and walking distance. Figure 9 (d) shows the recommended parking area result i.e. parking area address with parking price per hour decided by the system.

\subsection{Performance metrics}

To evaluate the performance of the proposed SPMS, this paper employs the following two metrics and compares the performance of it with the system proposed by Pham et al. [28] and Reservation based smart parking system (RSPS) [38]:

- Avg. Extra Driving Distance: It is defined as the extra distance travelled by the user while searching for the parking area from a particular parking area of his/her choice. This metric is considered as one of the important performance metrics as it is directly related with the amount of traffic congestion generated during searching of 


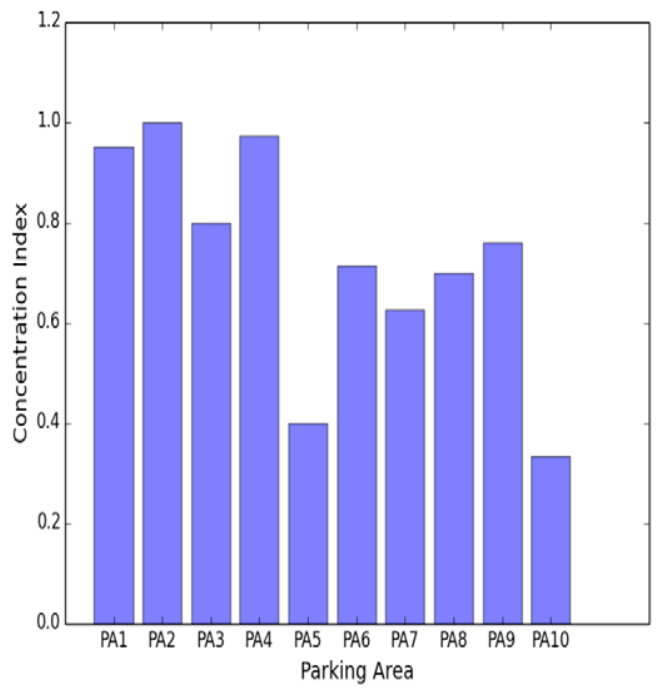

Fig. 7. Comparison of concentration index of different parking areas.

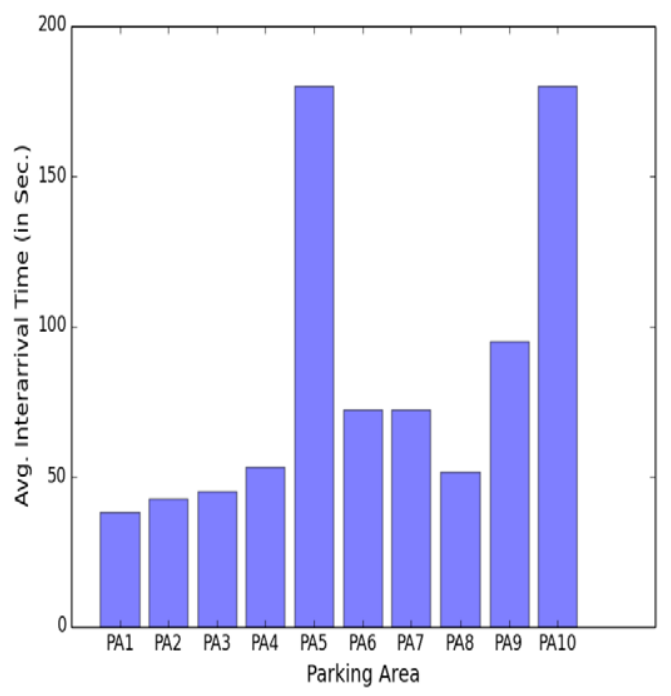

Fig. 8. Comparison of avg. Inter-arrival time of different parking areas.

parking space. Also, this metric has a major impact on amount of carbon emission in the environment resulting in increase of air pollution.

- Avg. Walking Distance: It is defined as the average distance walked by the users from the system selected parking area to his/her destination. In this proposed system, the user/driver has the choice to select a particular parking area based on his/her preferences. These preferences include the distance of parking area from the destination and the price of parking area per hour. Hence the user may choose the convenient parking area in terms of shortest walking distance from the destination.

\subsection{Performance evaluation}

To evaluate and compare the performance of the proposed system with the system proposed by Pham et al. [28] and RSPS [38] based on the above mentioned performance metrics, Python has been used to conduct the simulation. This paper simulates parking area reservation procedure for all the systems as per the scenario depicted in Fig. 10. 


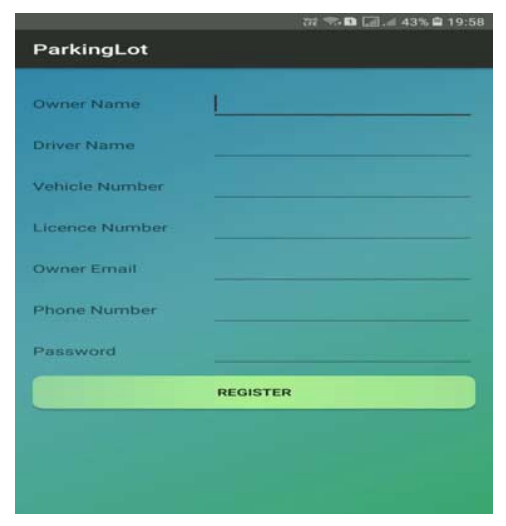

(a)

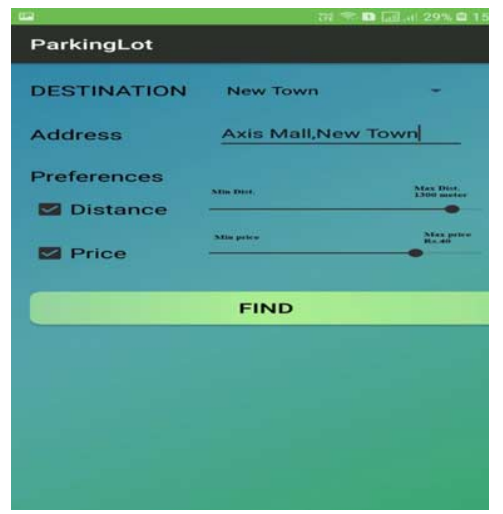

(c)

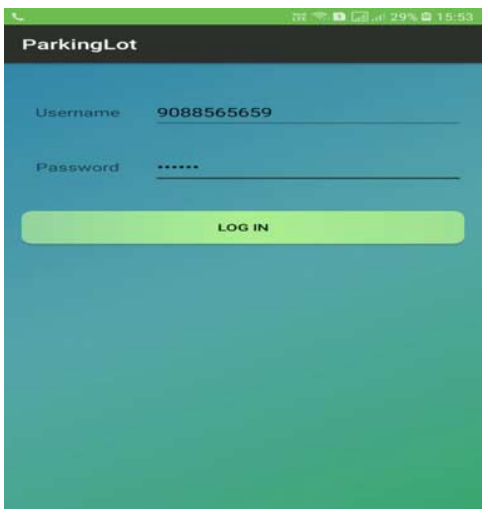

(b)

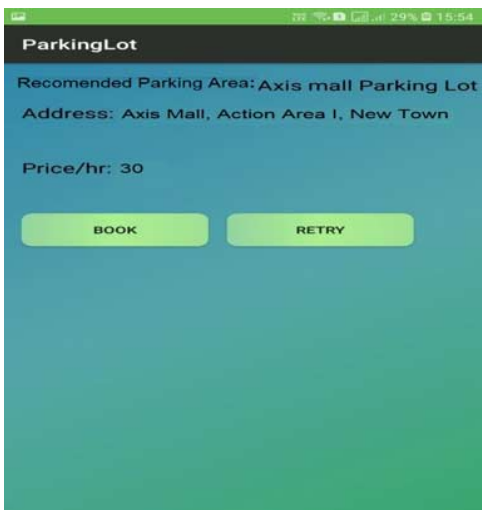

(d)

Fig. 9. Android interfaces: a) registration interface b) login interface c) request interface d) result interface.

\subsubsection{Performance evaluation of the proposed SPMS}

Considering there are five parking areas near a destination, each having capacity of five hundred parking spaces and distance between these parking areas are shown in Fig. 10. The paper simulates the system proposed by Pham et al. and RSPS based on the network model shown in Fig. 10 where different users coming to that particular destination over a time period looking for the parking area "P1" to park their vehicles as it is the nearest parking area from the destination. To simulate the proposed SPMS system, the same scenario has been employed.

Table 6 shows the comparison of average extra driving distance travelled by users in case of the system proposed by Pham et al. and RSPS with respect to the proposed system. Figure 11 plots the average extra driving distance with respect to time for all the above mentioned systems. The graph shows that average extra driving distance while searching a convenient parking area is much less in case of the proposed system as compared to the system proposed by Pham et al. [28] and RSPS [38]. Though, during non-rush hour (11:00 h to 14:00 h) RSPS perform slightly better than proposed SPMS system.

This is because during non-rush hour (11:00 $\mathrm{h}$ to 14:00 $\mathrm{h}$ ) when parking demand is low, RSPS reserves all the parking slots in "P1" which is nearer to the destination as long as space is available there. But the proposed SPMS not only optimize the usage of all the parking areas by reserving parking slots based on the parking occupancy ratio of all the parking areas but also keeps in mind the user's preferences. Even if the requested nearest parking area has an available parking slot, then also the proposed SPMS may not reserve that parking area, rather it will reserve a slot in another nearest parking area where the parking occupancy ratio is low in order to optimize the usage of all the parking areas. 


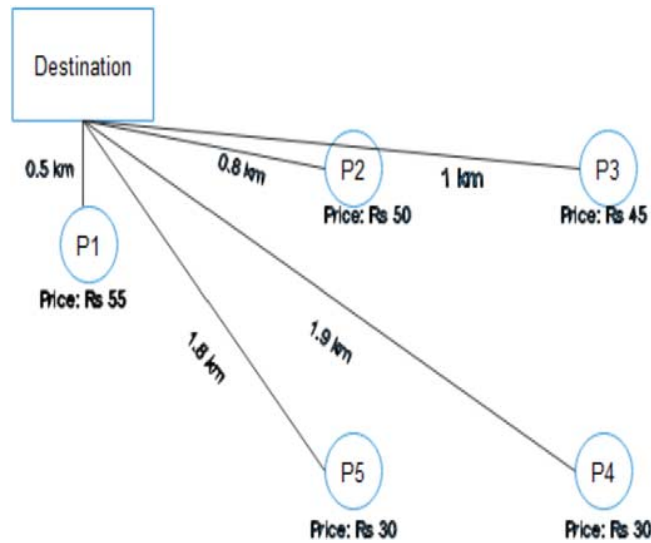

Fig. 10. Parking area distance from destination.

Table 6

Extra avg. driving distance by user

\begin{tabular}{lccc}
\hline \multirow{2}{*}{$\begin{array}{l}\text { Time } \\
\text { (24 hour format) }\end{array}$} & \multicolumn{3}{c}{ Extra avg. driving distance $(\mathrm{km})$} \\
\cline { 2 - 4 } & Pham et al. & MCPR & RSPS \\
\hline 11 & 0 & 0.06 & 0 \\
12 & 0.11 & 0.03 & 0.02 \\
13 & 0.17 & 0.04 & 0.03 \\
14 & 0.92 & 0.13 & 0.2 \\
15 & 1.43 & 0.2 & 0.3 \\
16 & 1.5 & 0.33 & 0.88 \\
17 & 2.22 & 0.58 & 1.21 \\
18 & 1.91 & 0.43 & 1.11 \\
19 & 1.6 & 0.3 & 0.89 \\
20 & 1.22 & 0.17 & 0.21 \\
21 & 0 & 0 & 0 \\
\hline
\end{tabular}

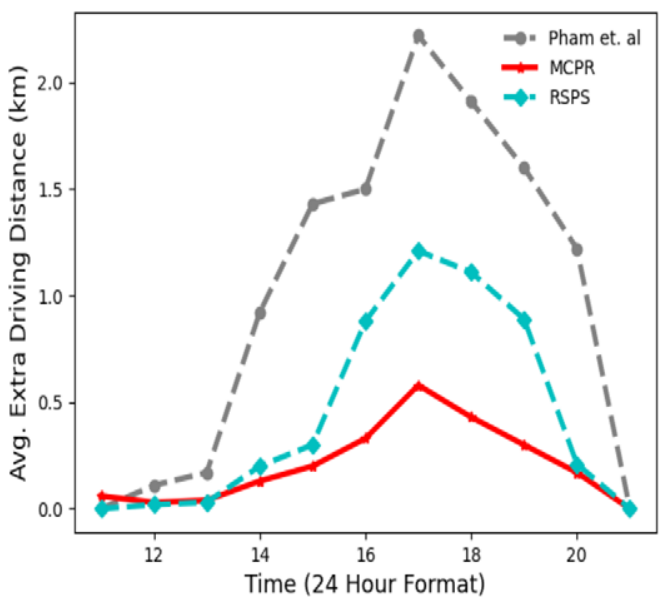

Fig. 11. Average extra driving distance. 
Table 7

Avg. extra walking distance travelled by user

\begin{tabular}{lccc}
\hline Time & \multicolumn{3}{c}{ Avg. Walking Distance $(\mathrm{km})$} \\
\cline { 2 - 4 }$(24$ hour format $)$ & Pham et al. & MCPR & RSPS \\
\hline 6 & 0.5 & 0.56 & 0.5 \\
7 & 0.52 & 0.53 & 0.48 \\
8 & 0.53 & 0.65 & 0.52 \\
9 & 0.87 & 0.63 & 0.53 \\
10 & 1.07 & 0.7 & 0.9 \\
11 & 1.06 & 0.83 & 1.01 \\
12 & 1.08 & 1.08 & 1.08 \\
13 & 1.09 & 0.92 & 0.99 \\
14 & 1.05 & 0.8 & 0.81 \\
15 & 0.99 & 0.67 & 0.62 \\
16 & 0.5 & 0.5 & 0.5 \\
\hline
\end{tabular}

But during peak hour (i.e. from 15:00 $\mathrm{h}$ to 19:00 $\mathrm{h}$ ) when the no. of vehicles coming to the destination increases, the average extra driving distance travelled by the user to find a parking area is increasing more sharply according to the system proposed by Pham et al. [28] as well as (RSPS) in [38] than the proposed SPMS system. This happens because most of the users look for the parking areas which are nearest to the destination and during peak hour all the nearest parking areas may already be occupied in [28] and [38]. In case the of system proposed by Pham et al. [28], when the user searches for a parking area, the system may direct him/her to the nearest parking area "P1" but after reaching the directed parking area, it may happen that the parking areas are already full, then the system again redirects the user to its neighboring parking area. That is why extra driving distance is maximum. In case of RSPS, as the system will satisfy all the parking requests nearer to the destination as long as space is there. So during the peak hour all the nearest parking areas may already be booked. Hence during peak hour, this system will reserve parking areas that are farther from the destination. But as this system already reserves the parking slot, so the average extra driving distance in case of the system proposed by RSPS is less than the system proposed by pham et al. but more than the proposed SPMS system which allocates the parking area based on MCPR algorithm. This result suggests that proposed car parking solution SPMS helps to reduce traffic congestion as well as air pollution which happens during searching for a parking area.

Table 7 shows the comparison of the average walking distance from the parking area to the destination by users for the system proposed by Pham et al., RSPS and proposed SPMS system. The graph in Fig. 12 shows that the average extra walking distance by the user is much less in the proposed system as compared to the system proposed by Pham et al. and RSPS. In case of the system proposed by the Pham et al. and RSPS, during peak hour (i.e. from 15:00 $\mathrm{h}$ to 19:00 $\mathrm{h}$ ) when the number of vehicles coming to the destination increases, the vehicles are directed to the parking area which are farther from the destination, as the nearby parking areas may already be filled before the peak hour and hence the users have to walk longer distance to reach the destination from the selected parking area. In the proposed SPMS system, parking areas are allotted to the users keeping in mind the user's preferences as well as space utilization factor of all parking areas. Hence during peak hours, the system can allot the nearby parking area to some of the users. That is why the average walking distance is least in case of the proposed SPMS system. However, from 11:00 $\mathrm{h}$ to 13:00 $\mathrm{h}$ the average walking distance is slightly higher in the proposed SPMS system than the Pham et al. [28] and RSPS [38], because the SPMS system will not reserve nearest parking area even if space is available as it reserves the parking areas keeping in mind the user's preferences as well as space utilization factor of all parking areas.

\subsubsection{Evaluation of proposed dynamic pricing model}

This section evaluates the performance of the proposed dynamic pricing model. As discussed in Section 3.2.3, the expectation is that the dynamic pricing model will generate more revenue as compared to fixed or static pricing scheme. To assess the performance of the proposed dynamic pricing model, some assumptions are made as shown in 


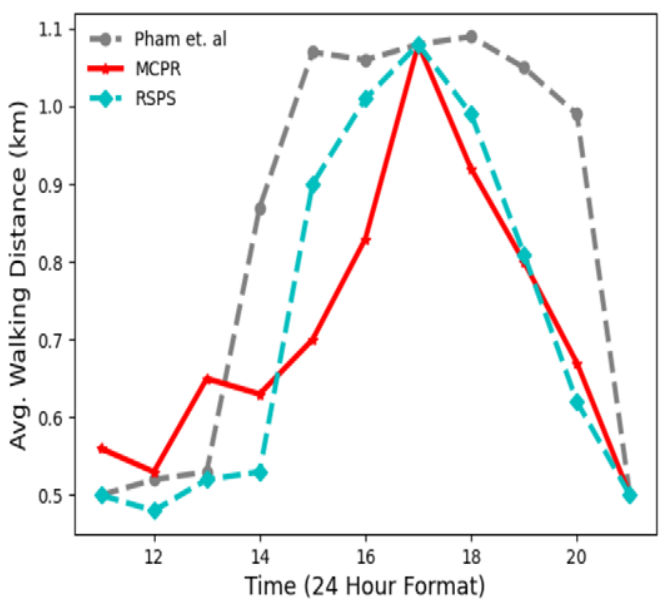

Fig. 12. Average extra walking distance.

Table 8

Simulation parameters

\begin{tabular}{lc}
\hline Parameters & Value \\
\hline Parking capacity & 200 \\
Operational cost & Rs. 30
\end{tabular}

Duration of parking (every vehicle) $1 \mathrm{~h}$

Constant k

Table 9

Simulation results in terms of price/h

\begin{tabular}{lccc}
\hline Occupancy status & Space availability & \multicolumn{2}{c}{ Price/hour (in Rs) } \\
\cline { 3 - 4 } & & Dynamic pricing & Static pricing \\
\hline 1 & 199 & 30.075 & 30 \\
20 & 180 & 32.925 & 30 \\
39 & 161 & 34.35 & 30 \\
58 & 142 & 35.775 & 30 \\
77 & 123 & 37.2 & 30 \\
96 & 104 & 38.625 & 30 \\
115 & 85 & 40.05 & 30 \\
134 & 66 & 41.475 & 30 \\
153 & 47 & 42.9 & 30 \\
172 & 28 & 44.325 & 30 \\
191 & 9 &
\end{tabular}

Table 8. The simulation result shown in Table 9 indicates that price is increasing gradually as space availability decreases in the dynamic pricing technique, whereas in fixed pricing technique the price remains constant irrespective of space availability status.

Table 10 shows that government or private organization can gain more revenue during rush hour if the system implements a dynamic pricing model than the fixed or static pricing.

Figure 13 and 14 shows the comparison of dynamic and static pricing technique in terms of price per hour of parking and revenue gain respectively.

The price of parking increases gradually when the number of vehicles increases in a parking area in case of a dynamic pricing scheme while the price of parking remains the same irrespective of number of vehicles present 
Table 10

Simulation results in terms of revenue

\begin{tabular}{lccc}
\hline Occupancy status & Space availability & \multicolumn{2}{c}{ Revenue/hour (in Rs) } \\
\cline { 3 - 4 } & & Dynamic pricing & Static pricing \\
\hline 1 & 199 & 1228.5 & 30 \\
20 & 161 & 1868.325 & 1170 \\
58 & 142 & 2535.225 & 1740 \\
77 & 123 & 3229.2 & 2310 \\
96 & 104 & 3950.35 & 2880 \\
115 & 85 & 4698.375 & 3450 \\
134 & 66 & 5473.575 & 4020 \\
153 & 47 & 6275.85 & 4590 \\
172 & 28 & 7105.2 & 5160 \\
191 & 9 & & 5730 \\
\hline
\end{tabular}

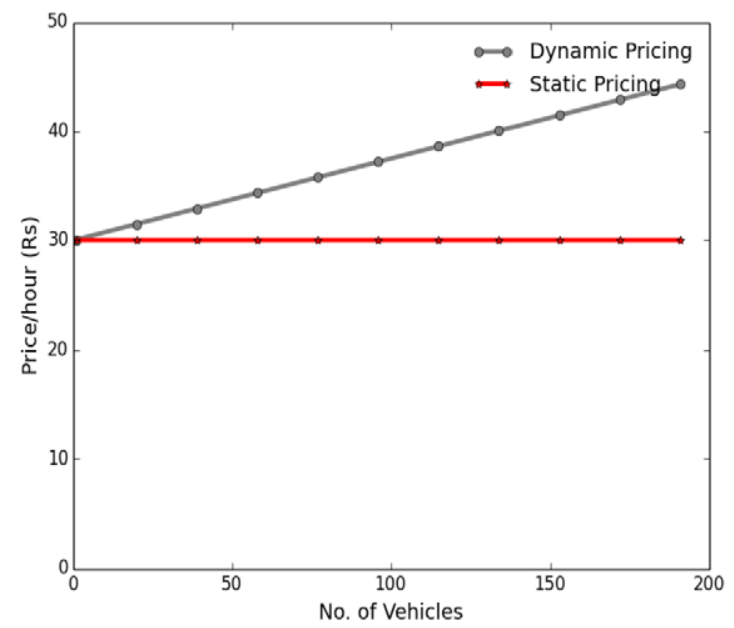

Fig. 13. Changes in price based on demand.

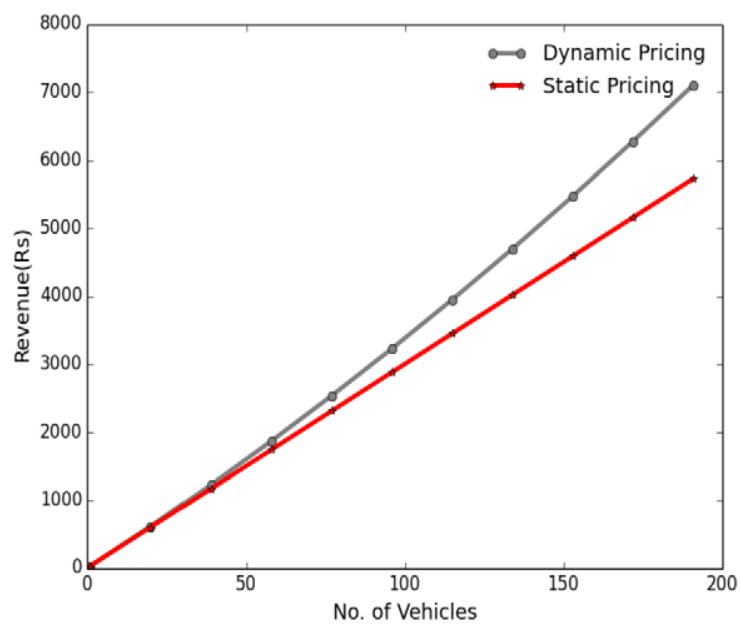

Fig. 14. Profit comparison. 


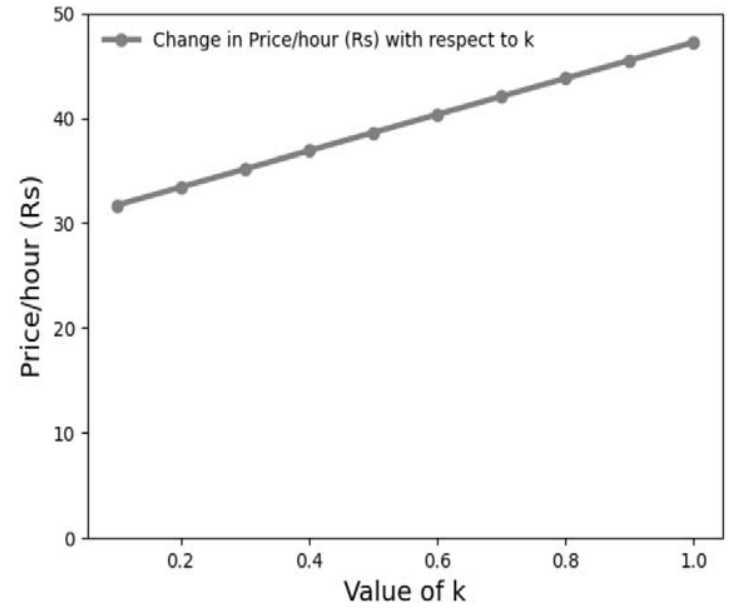

Fig. 15. Change in price with respect to $k$.

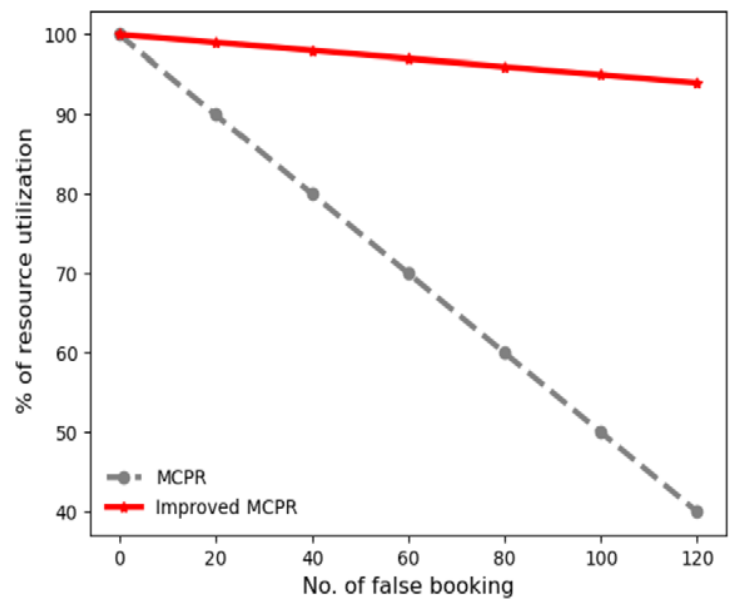

Fig. 16. Resource utilization in false booking

in a parking area as shown in Fig. 13. As the price of parking increases in dynamic pricing scheme, hence more revenue can be gained as compared to static pricing scheme and this is shown in Fig. 14. The price of parking can be adjusted by the parking owner here by changing the value of constant $k$. With the increasing value of $k$, the price of parking will also increase as shown in Fig. 15.

\subsubsection{Performance comparison of improved MCPR with MCPR algorithm}

This section compares the performance of MCPR algorithm and improved MCPR algorithm in terms of resource utilization with respect to number of false booking. False booking means, a parking area is booked but not used by the user. The MCPR algorithm has not considered the scenario when the user has not appeared and used the booked parking slot in a parking area. In that case, the MCPR algorithm will not cancel the booking and hence other users who want to use the same parking area will not get the space for parking. This leads to under-utilization of resources i.e. parking areas. But in improved MCPR, this problem is addressed as discussed in Section 4 and hence resources will be utilized in a much more efficient way. To simulate, the following scenario is considered: assume parking area $P A_{1}$ has 200 parking slots, at a particular time all parking slots of $P A_{1}$ are booked by the users and many more parking requests are there for $P A_{1}$. Also assume that, the new users who got the opportunity to book the parking slots in $P A_{1}$ due to cancellation of false bookings, $90 \%$ of them use that parking area. The simulation result shown in Fig. 16 indicates that even for false bookings, the utilization is much higher in improved MCPR algorithm whereas 
utilization is decreasing with an increase in number of false bookings in MCPR algorithm. For example, initially all the 200 parking slots of a parking area are booked and number of false booking is 20 . So in improved MCPR, once 3 hours of waiting window is over, another new 20 users can book those unused parking slots. But assume $90 \%$ of them use those parking slots. In that scenario, utilization will be $99 \%$.

\section{Conclusion}

This paper has proposed a smart parking management system based on the MCPR algorithm to allocate scarce parking resources. The system was implemented for enabling simulating the performance. The proposed SPMS system guides the users to find and reserve the most suitable parking area in a fair way keeping in view to minimize traffic congestion, excess fuel consumption and air pollution. The proposed system not only assists the drivers to find a proper parking space but it also helps the parking owner to be a part of the system. The proposed system outperforms the system proposed by Pham et al. [28] and RSPS [38] by considering two performance metrics: average extra driving distance and average walking distance. It has been seen that the average extra distance that the users have to drive in the proposed SPMS for searching a parking area is much less than the system proposed by Pham et al. [28] and in RSPS [38] and it helps to reduce traffic congestion, excess fuel consumption and air pollution. In the proposed system, the average walking distance from the selected parking area to his/her destination is also less than the systems proposed by Pham et al. [28] and RSPS [38]. It suggests that the SPMS system allocates the parking slots keeping user's comfort in mind as well. The Dynamic pricing model is used to determine the parking cost as it increases the revenue when the parking demand is high. The proposed system not only assists the government/private organization to gain more revenue but also keeps in mind the user's satisfaction and manages the available parking resources in a fair way. The system also assists the regulatory bodies to formulate better parking management strategies with the help of the survey data for parking areas.

\section{Conflict of interest}

The authors have no conflict of interest to report.

\section{References}

[1] L. Atzori, A. Iera and G. Morabito, The internet of Things: A survey, Computer Networks 54 (2010).

[2] V. Belton and T.J. Stewart, Multiple Criteria Decision Analysis: An Integrated Approach, Springer Science And Business Media, 2002.

[3] C. Benevolo, R.P. Dameri and B. D’Auria, Smart Mobility in Smart City. Action Taxonomy, ICT Intensity and Public Benefits, Vol. 11, Springer International Publishing, Switzerland, 2016, pp. 13-28.

[4] J. Bergh and S. Viaene, Unveiling smart city implementation challenges: The case of Ghent, Information Polity 21 (2015), 1-15. doi:10. 3233/IP-150370.

[5] N. Chaudhry, M. Yousaf and M. Khan, Indexing of real time geospatial data by IoT enabled devices: Opportunities, challenges and design considerations, Journal of Ambient Intelligence and Smart Environments 12 (2020), 1-32. doi:10.3233/AIS-200565.

[6] N. Chen, L. Wang, L. Jia, H. Dong and H. Li, Parking survey made efficient in intelligent parking systems, Elsevier Procedia Engineering 137 (2016), 487-495. doi:10.1016/j.proeng.2016.01.284.

[7] J. Chin, V. Callaghan and S.B. Allouch, The Internet-of-Things: Reflections on the past, present and future from a user-centered and smart environment perspective, Journal of Ambient Intelligence and Smart Environments 11(1) (2019), 45-69. doi:10.3233/AIS-180506.

[8] A.V. den Boer, Dynamic pricing and learning: Historical origins, current research, and new directions, Surveys in Operations Research and Management Science 20(1) (2015), 1-18. doi:10.1016/j.sorms.2015.03.001.

[9] S. Djahel, R. Doolan, G. Muntean and J. Murphy, A communications-oriented perspective on traffic management systems for smart cities: Challenges and innovative approaches, in: IEEE Communication Surveys and Tutorials, Vol. 17, 2015.

[10] M.-A. Doran and S. Daniel, Geomatics and smart city: A transversal contribution to the smart city development, Inf. Polity 19 (2014), 57-72. doi:10.3233/IP-140330.

[11] E. Ergazakis, K. Ergazakis, D. Askounis and Y. Charalabidis, Digital Cities: Towards an Integrated Decision Support Methodology, Telemat. Inf. 28(3) (2011). doi:10.1016/j.tele.2010.09.002.

[12] M. Gams, I. Gu, A. Harma, A. Munoz and V. Tam, Artificial intelligence and ambient intelligence, Journal of Ambient Intelligence and Smart Environments 11 (2019), 71-86. doi:10.3233/AIS-180508. 
[13] Y. Geng and C.G. Cassandras, A new smart parking system based on optimal resource allocation and reservations, in: 14th International IEEE Conference On Intelligent Transportation Systems Washington, DC, USA, 2011.

[14] J.R. Gil-Garcia, T. Pardo and T. Nam, What makes a city smart? Identifying core components and proposing an integrative and comprehensive conceptualization, Information Polity 20 (2015), 61-87. doi:10.3233/IP-150354.

[15] T. Giuffrea, S. Siniscalchia and G. Tesorierea, A novel architecture of parking management for smart cities, in: Fifth International Congress-Sustainability of Road Infrastructures, 2012.

[16] C. Gomez, S. Chessa, A. Fleury, G. Roussos and D. Preuveneers, Internet of Things for enabling smart environments: A technology-centric perspective, Journal of Ambient Intelligence and Smart Environments 11 (2019). doi:10.3233/AIS-180509.

[17] Z. Ji, I. Ganchev, M. O'Droma, L. Zhao and X. Zhang, A cloud-based car parking middleware for IoT-based smart cities: Design and implementation, Sensors (Basel, Switzerland) 14 (2014), 22372-22393. doi:10.3390/s141222372.

[18] A. Kianpisheh, N. Mustaffa, P. Limtrairut and P. Keikhosrokiani, Smart Parking System (SPS) Architecture Using Ultrasonic Detector, International Journal of Software Engineering and Its Applications 6 (2012).

[19] M. Koksalan, J. Wallenius and S. Zionts, Multiple Criteria Decision Making: From Early History to the 21st Century, World Scientific Books, Vol. 8042, World Scientific Publishing Co. Pte. Ltd., 2011, https://ideas.repec.org/b/wsi/wsbook/8042.html.

[20] A.O. Kotb, Y. Shen, X. Zhu and Y. Huang, IParker-a new smart car-parking system based on dynamic resource allocation and pricing, IEEE Transactions on Intelligent Transportation Systems 17 (2016), 2637-2647. doi:10.1109/TITS.2016.2531636.

[21] S. Lee, D. Yoon and A. Ghosh, Intelligent parking lot application using wireless sensor networks, in: 2008 International Symposium on Collaborative Technologies and Systems, 2008, pp. 48-57. doi:10.1109/CTS.2008.4543911.

[22] M. Liu, J. Naoum-Sawaya, Y. Gu, F. Lecue and R. Shorten, A distributed Markovian parking assist system, IEEE Transactions on Intelligent Transportation Systems 20 (2019), 2230-2240. doi:10.1109/TITS.2018.2865648.

[23] L. Luo and J.H. Peng, Dynamic pricing model for airline revenue management under competition, Systems Engineering-Theory and Practice 27 (2007), 15-25. doi:10.1016/S1874-8651(08)60065-4.

[24] M.A. Macadar, J.B. Porto and E. Luciano, Smart City: A Rigorous Literature Review of the Concept from 2000 to 2015 , Innovation and the Public Sector, Vol. 23, IOS Press, 2016, pp. 203-210. doi:10.3233/978-1-61499-670-5-203.

[25] L. Mainetti, I. Marasovic, L. Patrono, P. Solic, M. Stefanizzi and R. Vergallo, A novel IoT-aware smart parking system based on the integration of RFID and WSN technologies, International Journal of RF Technologies 7 (2016), 175-199. doi:10.3233/RFT-161523.

[26] A. Meijer and M.P.R. Bolivar, Governing the smart city: A review of the literature on smart urban governance, International Review of Administrative Sciences 82(2) (2016), 392-408. doi:10.1177/0020852314564308.

[27] S. Nayak, R. Renganathan, A. Nair, L.R. Saritha and L. Ladge, Smart car parking system using wireless sensor networks, in: 2020 Fourth International Conference on Inventive Systems and Control (ICISC), 2020, pp. 220-224. doi:10.1109/ICISC47916.2020.9171154.

[28] T.N. Pham, M. Tsai, D.B. Nguyen, C. Dow and D. Deng, A cloud-based smart-parking system based on Internet-of-Things technologies, IEEE Access 3 (2015), 1581-1591. doi:10.1109/ACCESS.2015.2477299.

[29] Z. Qian and R. Rajagopal, Optimal Occupancy-driven Parking Pricing Under Demand Uncertainties and Traveler Heterogeneity: A Stochastic Control Approach, Transportation Research Part B, Elsevier (2014), 144-165. doi:10.1016/j.trb.2014.03.002.

[30] R. Rana and F. Oliveira, Real-time dynamic pricing in a non-stationary environment using model-free reinforcement learning, Omega 47 (2014), 116-126. doi:10.1016/j.omega.2013.10.004.

[31] Z. Rehena, M.A. Mondal and M. Janssen, A multiple-criteria algorithm for smart parking: Making fair and preferred parking reservations in smart cities, in: Proceedings of the 19th Annual International Conference on Digital Government Research: Governance in the Data Age, DG.0 2018, Delft, The Netherlands, 2018, pp. 40:1-40:9.

[32] Z. Rehena, S. Roy and N. Mukherjee, Efficient data forwarding techniques in wireless sensor networks, in: 2013 3rd IEEE International Advance Computing Conference (IACC), 2013, pp. 449-457. doi:10.1109/IAdCC.2013.6514268.

[33] A. Roychowdhury, U. Nasim and G. Dubey, PAMPERING PARKING How to Manage Urban India's Parking Needs, 2018.

[34] A. Sahfutri, N.L. Husni, M. Nawawi, I. Lutfi, Evelina, A. Silvia and E. Prihatini, Smart parking using wireless sensor network system, in: 2018 International Conference on Electrical Engineering and Computer Science (ICECOS), 2018, pp. 117-122. doi:10.1109/ICECOS. 2018.8605241

[35] C. Tang, X. Wei, C. Zhu, W. Chen and J.J.P.C. Rodrigues, Towards smart parking based on fog computing, IEEE Access 6 (2018), 70172-70185. doi:10.1109/ACCESS.2018.2880972.

[36] V.W.S. Tang, Y. Zheng and J. Cao, An intelligent car park management system based on wireless sensor networks, in: 2006 First International Symposium on Pervasive Computing and Applications, 2006, pp. 65-70. doi:10.1109/SPCA.2006.297498.

[37] J. Vera, A. Quesada-Arencibia, C. Garcia, R. Moreno and F. Hernandez, An intelligent parking management system for urban areas, Sensors 16 (2016), 931. doi:10.3390/s16060931.

[38] H. Wang and W. Hey, A reservation-based smart parking system, in: The First International Workshop on Cyber-Physical Networking Systems, IEEE, 2011.

[39] J. Wolff, T. Heuer, H. Gao, M. Weinmann, S. Voit and U. Hartmann, Parking monitor system based on magnetic field sensors, in: 2006 IEEE Intelligent Transportation Systems Conference, 2006, pp. 1275-1279. doi:10.1109/ITSC.2006.1707398.

[40] A. Zanella, N. Bui, A. Castellani, L. Vangelista and M. Zorzi, Internet of things for smart cities, IEEE Internet of Things Journal 1(1) (2014), 22-32. doi:10.1109/JIOT.2014.2306328. 